\title{
Le pouvoir en restes
}

Gouverner par les déchets au Cameroun

Remnants of Power: Ruling through Waste in Cameroon

\section{Émilie Guitard}

\section{OpenEdition}

\section{Journals}

Édition électronique

URL : https://journals.openedition.org/tc/8149

DOI : $10.4000 /$ tc. 8149

ISSN : 1952-420X

Éditeur

Éditions de l'EHESS

\section{Édition imprimée}

Date de publication : 31 octobre 2016

Pagination : 386-389

ISBN : 9782713225291

ISSN : 0248-6016

Référence électronique

Émilie Guitard, «Le pouvoir en restes », Techniques \& Culture [En ligne], 65-66 | 2016, mis en ligne le 31 octobre 2016, consulté le 29 septembre 2022. URL : http://journals.openedition.org/tc/8149; DOI : https://doi.org/10.4000/tc.8149 


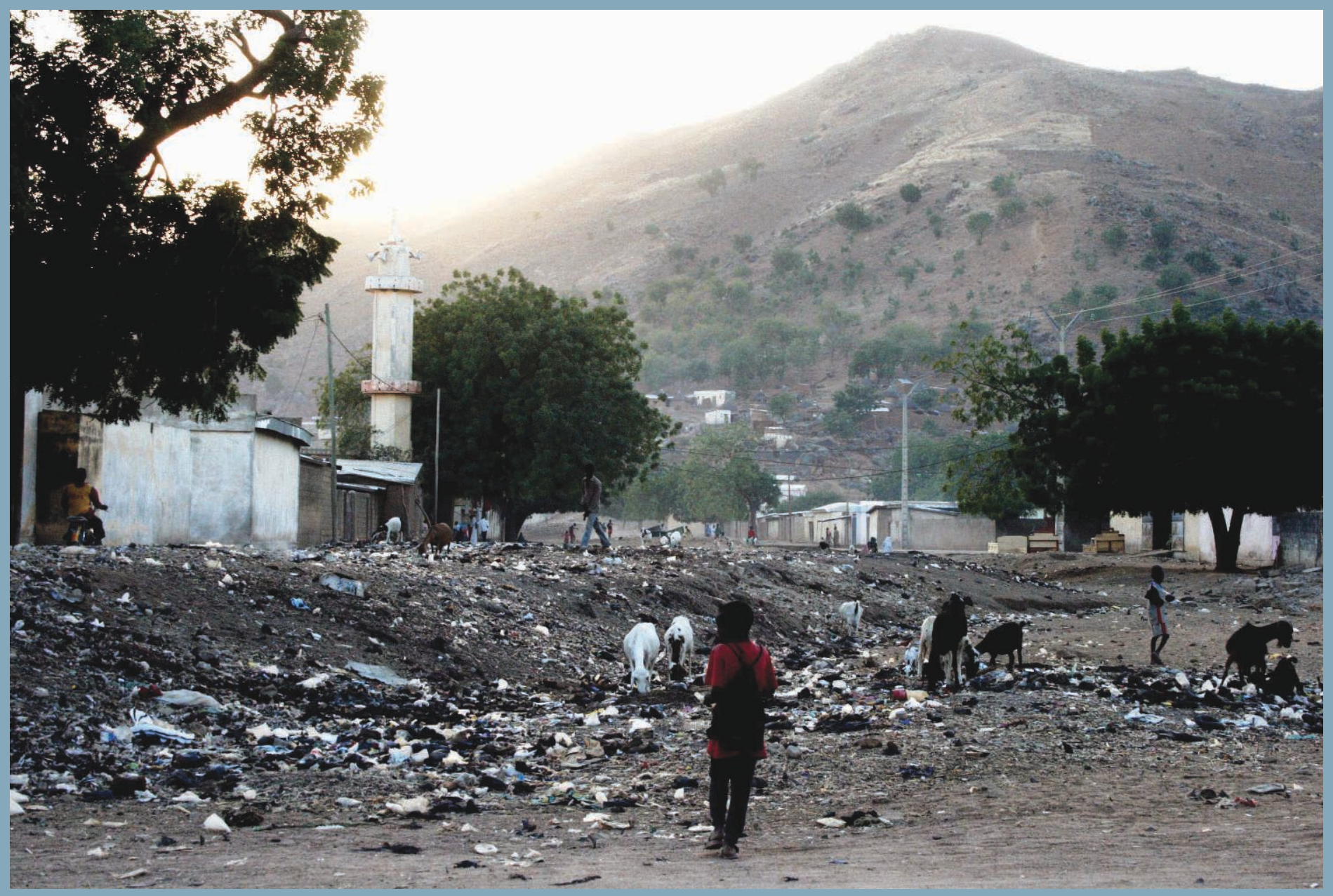




\section{Le pouvoir en restes Gouverner par les déchets au Cameroun}

À Garoua et Maroua, chefs-lieux des régions du Nord et de l'Extrême Nord du Cameroun, un proverbe dit que «le grand chef doit être comme le grand tas d'ordures». Partant de celui-ci, j'ai entrepris entre 2007 et 2014 de mettre en lumière l'intrication entre gestion des déchets et relations de pouvoir dans ce contexte urbain. Fondées au tournant du XIXe siècle par des conquérants peuls et musulmans descendus du Nord-Ouest, Maroua et Garoua sont élevées au xxe siècle, durant la colonisation, au rang de chefs-lieux de circonscription. À partir de l'indépendance du Cameroun en 1960, elles deviennent aussi des centres commerciaux et politiques majeurs pour la partie septentrionale du pays et le bassin du lac Tchad. Le développement rapide des activités et des populations de ces deux villes place la gestion des déchets au premier rang des problématiques à prendre en charge par les autorités à leur tête. Pourtant, à partir du milieu des années 1980, celles-ci s'avèrent progressivement incapables de collecter et de traiter les déchets domestiques et les eaux usées issus des ménages, des commerces, des industries, laissant de nombreux dépotoirs se développer dans le paysage urbain. En 2006, alors que je me rends pour la première fois à Garoua pour y étudier les représentations et les modes de gestion individuels et institutionnels des déchets, ceux-ci m’apparaissent jouer un rôle majeur dans les relations de pouvoir entre les différents habitants et les acteurs municipaux de cette ville et de Maroua, sa voisine et rivale de l'Extrême-Nord. Ce sentiment sera conforté en 2008, lorsqu'une société privée de collecte est mandatée par l'État camerounais pour reprendre en charge la gestion des déchets dans les deux villes.

Comment la gestion des objets et des substances déchus issus des individus, de leurs corps, de leur culture matérielle, de leurs activités domestiques quotidiennes, acquiert-elle dans ce contexte une dimension éminemment politique? Comment est-elle en retour traversée et prise dans les relations de pouvoir non seulement verticales, entre institutions et individus et du haut au bas de l'échelle hiérarchique locale, mais aussi horizontales, entre personnes de même statut revendiquant une autorité sur des espaces d'envergures diverses, de l'habitation à la ville, en passant par la rue et 
le quartier? Les réponses à ces questions paraissent se situer dans une conception particulière des liens qui unissent les corps et leurs excrétions, les objets et les espaces de vie des individus. Elles résident aussi dans les pratiques qui l'accompagnent et participent au détachement entre les corps, ce qui en tombe et les choses qui y ont été un temps inscrites, puis au dépôt de ces substances, matières et objets déchus dans l'espace, selon une cartographie particulière. Le cas particulier des villes nord camerounaises de Garoua et Maroua permet alors de conceptualiser une façon alternative de penser le déchet et le déchu, non plus seulement en termes matériels, techniques, classificatoires, spatiaux ou temporels, mais comme un état des choses, résultant d'un processus de rupture complexe, dynamique, culturellement et historiquement défini, entre celles-ci et soi-même.

Le proverbe «le grand chef doit être comme le grand tas d'ordures», spontanément et régulièrement mobilisé par mes interlocuteurs à propos des rapports entre exercice du pouvoir et gestion des déchets, résume par un effet de double sens les liens étroits qui unissent, dans cette partie du globe, celui qui possède une autorité sur un espace social et matériel donné et les déchets qui y sont produits et accumulés ou en sont au contraire évacués. Il reçoit en effet deux types d'exégèses. La première, et la plus fréquente, formulée essentiellement par des élites politiques municipales, avance que l'association métaphorique entre le détenteur du pouvoir et une grande accumulation de déchets vise à exprimer l'attitude hiératique à adopter par les gouvernants dans les rapports de force avec leurs administrés. Cette injonction à recevoir toutes les plaintes sans broncher, comme un grand tas d'ordures, n'est pas aussi sans faire écho à l'immobilisme des pouvoirs publics tels qu'ils sont décriés par les populations citadines de nombreux pays africains, à commencer par le Cameroun. Il est tentant d'y voir alors une évocation cynique de la crise de la « gouvernance» que connaissent les villes africaines depuis le début des années 1980, et dont les dysfonctionnements de la gestion municipale des déchets sont vus comme révélateurs. La seconde exégèse de notre proverbe émane d'hommes de religion, théologiens musulmans comme marabouts, et apporte deux nouveaux éléments à la compréhension des rapports liant exercice du pouvoir et gestion des déchets dans les villes du Nord du Cameroun. D'abord la notion de «force», attribuée dans les religions locales comme dans le registre ésotérique musulman à une grande variété de restes accumulés en importante quantité, depuis longtemps, en un monticule; «force» que le chef se devrait également de posséder. Ensuite, la nature de la relation entre un chef et un grand tas d'ordures, pensée sur un mode non plus seulement métaphorique, mais aussi consubstantiel.

Une continuité semble ainsi être établie par les citadins de Garoua et Maroua entre les déchets et les détenteurs d'une autorité sur un espace spécifique. On peut distinguer schématiquement cinq grands régimes, développés et empilés, sans nécessairement se contredire, entre le xviII siècle environ et nos jours, qui déterminent dans ces deux villes nord camerounaises la gestion des déchets et son caractère politique. À partir de ce cas particulier, il paraît alors possible de nuancer la célèbre assertion de M. Douglas, arguant que «la saleté [et par extension le déchet], c'est quelque chose qui n'est pas à sa place» (2001: 55): celui-ci reçoit ici toujours une place qui lui est spécifique, et par là un statut à part entière, qui en fait un instrument puissant de gouvernement, de soi et des autres. 


\section{En ligne}

Retrouvez l'article complet sur revues.org, TechniquesE Culture 65-66 « Réparer le monde. Excès, reste et innovation »: http://tc.revues.org/

\section{I'auteure}

Émilie Guitard est anthropologue et chargée de mission Recherche au sein de l'Institut Français de Recherche en Afrique (IFRA, CNRS/MAEDI) basé à Ibadan, au Nigéria. Ses recherches portent sur les relations à l'environnement dans les contextes urbains africains. Dans le cadre d'une thèse d'anthropologie (université de Paris-Ouest Nanterre La Défense/LESC), elle a pu travailler avec les citadins et les autorités municipales de Garoua et Maroua (Cameroun), sur les représentations et pratiques de gestion des déchets, en lien avec les relations de pouvoir.

\section{Iconographie}

Crédits photographiques: (c) É. Guitard.

\section{Pour citer cet article}

Guitard, É. 2016 «Le pouvoir en restes. Gouverner par les déchets au Cameroun», TechniquesECulture 65-66 « Réparer le monde. Excès, reste et innovation», p. 386-389.

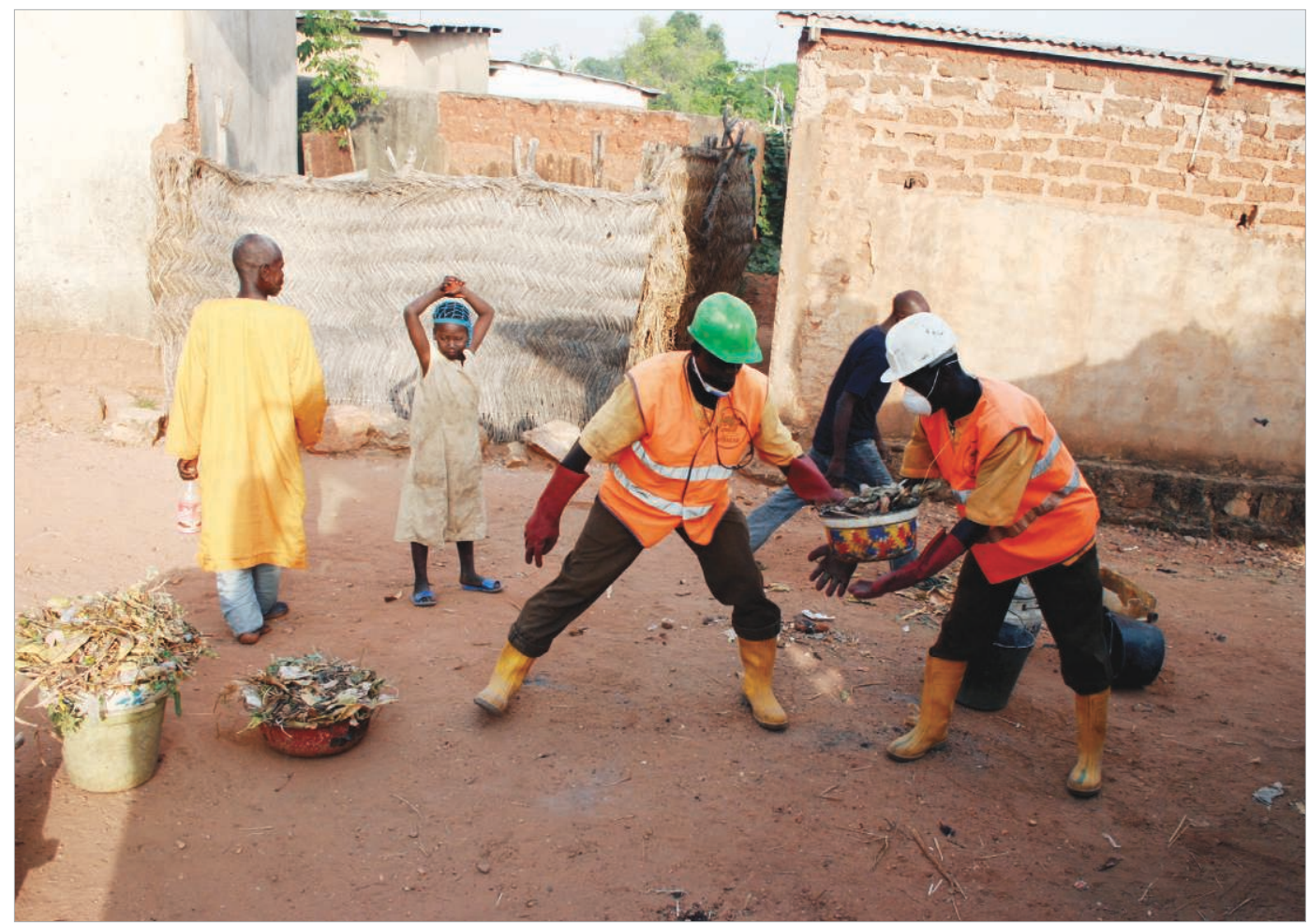

Collaboration entre des éboueurs et des citadins lors de la collecte porte-à-porte, Garoua, novembre 2009. 